\title{
LIPÍDIOS EM GRÃOS DE CAFÉ *
}

REGINA C. A. LAGO **

Nesta revisão são abordados os aspectos referentes ao teor, ao uso e à composição dos lipídios presentes em grãos de café arábica e robusta, tanto crus como torrados e em alguns de seus derivados. Comentam-se as principais diferenças entre as espécies no tocante aos lipídios e relatam-se os estudos sobre possíveis implicações à saúde por parte dos principais componentes do material insaponificável, o cafestol e o caveol. O teor dos lipídios em grãos crus é diferente dos torrados. A composição dos lipídios varia entre espécies e conforme autores. Se apenas a composição em ácidos graxos fosse considerada, na qual predominam os ácidos linoléico e palmítico, o óleo de café deveria exibir ponto de fusão mais elevado. A principal diferenciação entre as espécies está no teor e na composição do material insaponificável, sobretudo no que diz respeito aos álcoois diterpênicos, cafestol e caveol, e seus ésteres. A estes tem sido atribuído efeito hipercolesterolêmico, conseqüência de ingestão da bebida não-filtrada.

PALAVRAS-CHAVE: COFFEA; CAFESTOL; CAVEOL; CAFÉ SOLÚVEL.

\section{INTRODUÇÃO}

A escassez de dados sobre óleos de café publicados no Brasil, a dificuldade de obtenção e a dispersão de dados publicados no exterior, aliados ao recente incremento à pesquisa de café no país, pelo Consórcio Brasileiro de Pesquisa e Desenvolvimento do Café, motivaram este trabalho de revisão.

A planta do café pertence à família das Rubiáceas e ao gênero Coffea. As duas espécies de importância comercial são a Coffea arábica Linn. e a C. canephora Pierre ex Froehner, conhecidas como arábica e robusta,

* Trabalho financiado pelo Consórcio Brasileiro de Pesquisa e Desenvolvimento do Café.

** D. Sc. em Ciência de Alimentos, Pesquisadora da Embrapa Agroindústria de Alimentos, Rio de Janeiro, RJ. (e-mail: lago@ctaa.embrapa.br). 
respectivamente. Entre as variedades de arábica (a amarela já não é mais muito cultivada) encontram-se a Caturra, Mundo Novo (híbrido de Bourbon e Sumatra) e a Catuai. A variedade mais popular de robusta é a Kouilouensis ou Conillon (39). No Brasil, entre as variedades de café arábica encontram-se a Acaiá, Catuai vermelho, Catuai amarelo, Bourbon vermelho e B. amarelo.

O café arábica é mais valioso por oferecer sabor mais apurado. É fácil distinguir entre grãos crus de café arábica e robusta, pelas diferenças de tamanho e cor. Todavia, estas diferenças deixam de existir após a torrefação e moagem dos grãos. Outras alternativas devem ser buscadas para esta distinção.

Os lipídios de grãos de café verde ("o óleo de café") estão presentes, substancialmente, no endosperma e pequena quantidade de ceras encontra-se na camada externa do grão.

O tipo de extração e o solvente utilizado na mesma influenciam não só o rendimento como também a qualidade do óleo de café. A não ser que especificado de outra maneira, os óleos de café considerados nesta revisão foram extraídos com éter de petróleo de baixo ponto de ebulição e/ou hexano, em extrator Soxhlet. A Tabela 1 apresenta alguns dados sobre teor de lipídios em espécies de café. A determinação do óleo de café pode ser antecedida, ou não, pela deceração que é conduzida, normalmente, por extração dos grãos inteiros, com clorofórmio, por curto período de tempo.

\section{TABELA 1 - TEOR DE LIPÍDIOS EM GRÃOS DE CAFÉ (\%, BASE SECA)}

\begin{tabular}{lccccc}
\hline Tipo do grão & A & B & C & D & E \\
\hline Arábica verde & $12-18$ & 13,62 & $12,0-20,0$ & $15 \pm 0,78 \%$ & $14,2-16,8$ \\
Arábica torrado & $14,5-20,0$ & & & & \\
Robusta verde & $9,0-13,0$ & 9,47 & $9,0-17,0$ & $10 \pm 1,41 \%$ & $7,2-11,0$ \\
Robusta torrado & $11,0-16,0$ & & & & \\
Ceras & & & & 0,25 & \\
\hline
\end{tabular}

A) CLIFFORD, M.N. apud SMITH (37); B) WURZIGER (45): 3 amostras arábica (umidade média 7,92\%) e 6 robusta (umidade média 8,08\%); C) CARRERA et al. (5): teor médio em robusta $12 \%$ e em arábica $15,0 \%$; D) STREULI, H. apud FOLSTAR (9) : óleo extraído após tratamento dos grãos moídos com ácido. O teor de ceras apresentado equivale a 1,5$2,5 \%$ do óleo de café total; E) KROPLIEN, U. apud FOLSTAR (9). 
Segundo LERCKER et al. (26) o teor de lipídios aumenta após a torração devido, sobretudo, à destruição de carboidratos durante o processamento térmico. No arábica o aumento observado foi de 11,4 para $15,4 \%$ e no robusta de 6,1 para 9,6\%. Estes autores analisaram os lipídios totais por cromatografia gás-líquido por inserção direta (CGL), em coluna de vidro recoberta com SE-52, 0,10-0,15 $\mu \mathrm{m} \times 25 \mathrm{~m} \times 0,32 \mathrm{~mm}$, faixa de temperatura de $120-350^{\circ} \mathrm{C}$, programação de $10^{\circ} \mathrm{C} /$ min e detector FID a $350^{\circ} \mathrm{C}$, tendo observado os valores mostrados na Tabela 2.

\section{TABELA 2 - PRINCIPAIS CLASSES DE LIPÍDIOS EM GRÃOS DE CAFÉ}

\begin{tabular}{lcccc}
\hline CLASSE DE LIPÍDIOS & \multicolumn{2}{c}{ CAFÉ ARÁBICA } & \multicolumn{2}{c}{ CAFÉ ROBUSTA } \\
& Cru & Torrado & Cru & Torrado \\
\hline Ácidos graxos livres & 0,95 & 0,72 & 0,98 & 0,09 \\
Não-Identificados & 0,53 & 0,86 & $\operatorname{tr}$ & $\operatorname{tr}$ \\
Esteróis & 0,06 & 0,06 & $\operatorname{tr}$ & $\operatorname{tr}$ \\
DG + AD & 15,46 & 14,15 & 7,04 & 10,95 \\
TG + E & 83,00 & 84,21 & 91,98 & 88,95 \\
& & & & \\
\hline
\end{tabular}

$\mathrm{DG}$ = diacilgliceróis; $\mathrm{AD}$ = álcoois diterpênicos; $\mathrm{TG}$ = triacilgliceróis; $\mathrm{E}$ = outros ésteres. $\operatorname{tr}=$ quantidades traço, nas condições do método utilizado.

Fonte: LERCKER et al. (26).

O óleo de café não contém somente triacilgliceróis, mas também proporção considerável de outros componentes lipídicos específicos.

CALZOLARI e CERMA (3) observaram que o teor de ácidos graxos livres no óleo varia de 0,5 a 4,2\% e que a torrefação eleva este valor em 1 a 2 vezes.

RAVINDRANATH et al. (34) citam valores bastante variáveis para algumas características do óleo dos quatro grupos de óleo de café que estudaram (Tabela 3). 


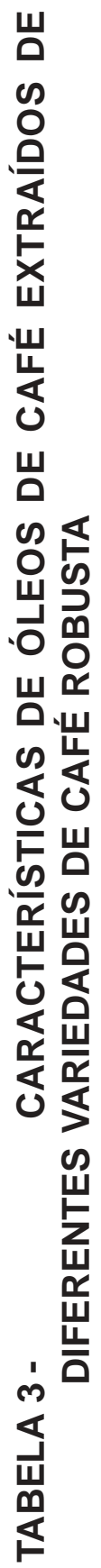

\begin{tabular}{|c|c|c|c|c|c|c|}
\hline \multirow{3}{*}{$\nabla$} & ญ్రి & ळo & & 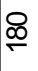 & $\stackrel{\sim}{\stackrel{N}{N}}$ & $\infty$ \\
\hline & 음 & ฮู & & 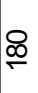 & $\stackrel{0}{N}$ & $N$ \\
\hline & गे & $\underset{\sigma}{\Phi}$ & & 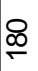 & $\begin{array}{l}0 \\
\stackrel{N}{N}\end{array}$ & $\stackrel{0}{N}$ \\
\hline \multirow{3}{*}{$m$} & ত্তু & $\underset{\sigma}{\sigma}$ & 足 & హㅁ & م. & مَ \\
\hline & 음 & کీ & ○্ & कБ & 음 & ת) \\
\hline & $\frac{2}{0}$ & बू & ద̊ & 호 & $\frac{\sigma_{-}}{\mp}$ & $\ddot{\omega}$ \\
\hline \multirow{3}{*}{ N } & ণ্ডু⿱ & fo & م & ষ্ণ & $\stackrel{\sim}{\mathscr{m}}$ & $\overline{0}$ \\
\hline & $\begin{array}{l}\text { 음 } \\
\text { 는 } \\
\text { 음 }\end{array}$ & ঠీ & & & ले & $\underset{0}{\sigma}$ \\
\hline & 림 & 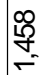 & $\begin{array}{l}0 \\
\Phi \\
\infty\end{array}$ & ஜ & $\widehat{N}$ & $\begin{array}{l}\Omega \\
1 \\
1\end{array}$ \\
\hline \multirow{3}{*}{$\Gamma$} & శ్రి & $\underset{-}{\ell}$ & 요 & ஜ & $\frac{\Omega}{5}$ & $\stackrel{m}{\sigma}$ \\
\hline & 음 & 疍 & $\dot{\sim}^{+}$ & প্ & $\stackrel{\Omega}{=}$ & ल) \\
\hline & $\frac{2}{0}$ & $\underset{f}{\mathscr{q}}$ & $\stackrel{0}{\infty}$ & ళ్ర & ô & No \\
\hline 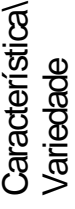 & & z & $\begin{array}{l}\frac{8}{8} \\
\frac{8}{8} \\
8 \\
\frac{8}{0} \\
.0\end{array}$ & ci & $\bar{\Sigma}$ & $\begin{array}{l}\frac{1}{8} \\
\frac{0}{0} \\
0 \\
0 \\
0 \\
8 \\
\frac{8}{0} \\
\text { 으 }\end{array}$ \\
\hline
\end{tabular}

હ্ঠ

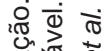
- త్ర শ্তে শ্র

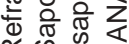
ฯ ஸ口 ญ 웜 뜬

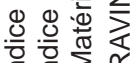
드드 $\sum_{\|}$ 䠉立 
SZPIZ et al. (40) encontraram valores altos para a acidez de 1,9 a 6,7\%. O tempo de armazenagem, que antecede o processamento, certamente exerce influência no teor de ácidos graxos livres e, conseqüentemente, no teor das demais classes lipídicas. A faixa encontrada para triacilgliceróis foi de 58,80 a $78,05 \%$ e para monoésteres de cafestol e caveol de 10,61 a $18,98 \%$. Para FOLSTAR (9) os valores para estas classes são: triacilgliceróis $(75,2 \%)$; ésteres de álcoois diterpênicos com ácidos graxos $(18,5 \%)$, álcoois diterpênicos $(0,4 \%)$, ésteres de esteróis com ácidos graxos $(3,2 \%)$, esteróis $(2,2 \%)$, tocoferóis $(0,04-0,06 \%)$, fosfatídios $(0,1-$ $0,5 \%)$ e derivados da hidroxitriptamina $(0,6-1,0 \%)$.

RAVINDRANATH et al. (34) encontraram teor médio de fosfatídios de 0,50\% em 4 amostras. REWALD (35) relatou valores mais elevados, entre 1,16 e 2,50\% para cafés verdes do Brasil, de Camarões, do Quênia, de Uganda e de Madagascar. Em cafés torrados, a faixa encontrada foi de $0,2-0,4 \%$.

O óleo de café produzido pela Macsol (4) é definido como "óleo aromático, extraído dos mais finos grãos de café, pelo processo de prensagem". Trata-se de "líquido viscoso, de cor marrom" que apresenta as seguintes características físico-químicas: Umidade e voláteis $=<2 \%$; Densidade relativa = 0,9-1,2 $\left(25^{\circ} \mathrm{C}\right)$; Índice de Refração = 1,46-1,49 $\left(25^{\circ} \mathrm{C}\right)$; Ácidos graxos livres $=3-5,5 \%$; Sedimentos $=<5 \mathrm{mg} / 3 \mathrm{~g}$; Viscosidade = máxima $300 \mathrm{cps}\left(25^{\circ} \mathrm{C}\right)$.

\section{COMPOSIÇÃO EM ÁCIDOS GRAXOS}

Existem diferenças acentuadas entre a composição dos ácidos graxos no óleo e na cera. LERCKER et al. (27) determinaram, por cromatografia a gás de alta resolução (CGAR), usando coluna capilar de SP-2340 (30 m), a composição em ácidos graxos de diversas amostras de café, incluindo café descafeinado (Tabela 4), cujos resultados assemelharamse aos obtidos por FOLSTAR, apud FOLSTAR (9). Os dados sobre a composição em ácidos graxos de óleos de café na literatura são escassos.

A composição triacilglicerólica determinada experimentalmente por LERCKER et al. (27) e os dados fornecidos por FOLSTAR (9), resultantes de cálculo baseado na distribuição 1,3-casual, mostraram boa correlação (Tabela 5). Os triacilgliceróis majoritários dipalmitoil-linoleil-glicerol (PLiP); dilinoleil-palmitoil-glicerol (PLiLi); palmitoi-oleoil-linoleil-glicerol (POLi) palmitoil-linoleil-estearil-glicerol (PLIS), derivados dos ácidos linoléico e palmítico refletem a composição dos respectivos ácidos graxos. 


\section{TABELA 4 - COMPOSIÇÃO EM ÁCIDOS GRAXOS (\%) DE ÓLEO E CERA DE CAFÉ}

\begin{tabular}{lccc}
\hline \multicolumn{1}{c}{ Ácido } & Cera $^{a}$ & Óleo $^{a}$ & Óleo $^{\circ}$ \\
\hline C14:0 (M)-Mirístico & 1,5 & $\operatorname{tr}$ & - \\
\hline C16:0 (P)-Palmítico & 24,5 & 31,1 & $32,1-33,2$ \\
C18:0 (S)-Esteárico & 6,5 & 9,6 & $7,5-8,2$ \\
C18:1 (O)-Oléico & 4,8 & 9,6 & $8,2-12,5$ \\
C18:2 (Li)-Linoléico & 23,8 & 43,1 & $42,6-46,2$ \\
C18:3 (Ln)-Linolênico & $\operatorname{tr}$ & 1,6 & $0,9-1,4$ \\
C20:0 (A)-Araquídico & 14,1 & 4,1 & $2,6-3,3$ \\
C20:1 (G)-Gadoleico & - & - & $0,1-0,4$ \\
C22:0 (B)-Behênico & 21,0 & 0,9 & $0,5-0,7$ \\
C24:0 (Lg)-Lignocérico & 3,7 & $\operatorname{tr}$ & $0,1-0,3$ \\
\hline
\end{tabular}

$\mathrm{a}=$ FOLSTAR, apud FOLSTAR (9); b = LERCKER et al. (27); tr = traços (valores nãoquantificados nas condições da análise).

\section{TABELA 5 - COMPOSIÇÃO TRIACILGLICERÓLICA (\%) DE ÓLEOS DE CAFÉ}

\begin{tabular}{lcc}
\hline Triacilglicerol & LERCKER et al. (27) & FOLSTAR (9) \\
\hline PPP & & 0,7 \\
PPS & $3,6-4,8$ & 0,8 \\
POP & $31,2-34,9$ & 5,9 \\
P LiP & $1,1-1,6$ & 28,8 \\
POS & $9,4-11,5$ & 1,8 \\
PLiS & $0,5-1,1$ & 9,3 \\
POO & $9,1-12,2$ & 0,6 \\
POLi & $21,7-26,0$ & 8,5 \\
PLiLi & $0,3-0,7$ & 27,5 \\
SOS & $3,1-4,2$ & 0,1 \\
SLiS & $0,6-1,2$ & 0,7 \\
SOLi & $2,8-3,9$ & 1,3 \\
SLiLi & $1,5-2,4$ & 0,1 \\
OOO & $1,9-2,5$ & 0,3 \\
OLiO & $1,5-3,6$ & 2,7 \\
OLiLi & & 6,7 \\
LiLiLi & &
\end{tabular}

LERCKER et al. (27): valores obtidos experimentalmente; FOLSTAR (9): valores calculados com base na composição em ácidos graxos, distribuição 1,3-casual. $\mathrm{P}=$ palmítico; $\mathrm{S}$ = esteárico; $\mathrm{O}=$ oléico; $\mathrm{Li}$ = linoléico.

SZPIZ et al. (40) observaram, em café arábica, diferenças marcantes entre a composição em ácidos graxos dos triacilgliceróis e dos monoésteres de cafestol e caveol, mas ainda com predominância do ácido palmítico (nos monoésteres) e do linoléico (nos triacilgliceróis). KAUFMANN \& HAMSAGAR (21) também encontraram valores diferenciados para os ácidos graxos constituintes dos triacilgliceróis e monoésteres de cafestol e caveol (Tabela 6). 


\section{TABELA 6 - COMPOSIÇÃO EM ÁCIDOS GRAXOS EM MONOÉSTERES DE CAFESTOL E CAVEOL (ME) E TRIACILGLICERÓIS (TAG) DE ÓLEO DE CAFÉ}

\begin{tabular}{lcccccccc}
\hline FRAÇÃO & \multicolumn{7}{c}{ ÁCIDOS GRAXOS (\% RELATIVA) } \\
\cline { 2 - 9 } & C14:0 & C16:0 & C18:0 & C18:1* & C18:2 & C18:3 & C20:0 & C22:0 \\
\hline TAG $^{\text {a }}$ & $0-0,17$ & $24,86-38,02$ & $7,74-12,66$ & $9,86-13,72$ & $43,16-49,22$ & $0-1,99$ & $0,36-4,38$ & $0-1,02$ \\
ME $^{\mathrm{a}}$ & $0-1,23$ & $45,20-54,50$ & $11,44-14,95$ & $8,58-11,95$ & $11,22-19,56$ & $0-0,40$ & $0-8,31$ & $0-2,81$ \\
TAG $^{\text {b }}$ & 0,2 & 33,3 & 7,3 & 6,6 & 47,7 & 1,7 & 2,5 & 0,5 \\
ME $^{\text {b }}$ & 1,5 & 50,2 & 8,9 & 7,2 & 25,8 & 0,8 & 4,5 & 1,0 \\
\hline
\end{tabular}

a SZPIZ et al. (40); ${ }^{b}$ KAUFMANN \& HAMSAGAR (21).

\section{MATÉRIA INSAPONIFICÁVEL}

O teor de matéria insaponificável (MI) em óleos vegetais é, em geral, ao redor de $1 \%$. No óleo de café este valor é anormalmente alto, podendo chegar a $12 \%$, segundo KHAN \& BROWN (24). RAVINDRANATH et al. (34) citam valores entre 9,0 e 13,4\% de matéria insaponificável, sem destacar diferenças entre espécies, grãos verdes e torrados ou borra preparada em laboratório.

Os principais constituintes do material insaponificável são dois álcoois diterpênicos, cafestol $\left(\mathrm{C}_{20} \mathrm{H}_{28} \mathrm{O}_{3}\right)$ e caveol $\left(\mathrm{C}_{20} \mathrm{H}_{26} \mathrm{O}_{3}\right)$, cuja estrutura foi elucidada por DJERASSI et al. (7) e que ocorrem na forma livre ou como monoésteres de ácidos graxos (Figura 1).

De acordo com a Agência Internacional para Pesquisa de Câncer (17) o teor total de diterpenos é de 1,3\% p/p em café verde arábica e $0,2 \%$ no robusta.

NACKUNSTZ \& MAIER (29) quantificaram $6 \mathrm{~g}$ de cafestol e $3 \mathrm{~g}$ de caveol em $1 \mathrm{~kg}$ de café arábica verde. Em duas amostras de robusta encontraram $2 \mathrm{~g} / \mathrm{kg}$ de cafestol e nenhum caveol. Na verdade, o caveol está também presente em cafés robusta, porém em quantidades baixas.

Em trabalho bem elaborado, PETTITT JR. (31) menciona a controvérsia entre ausência e baixa ocorrência de caveol no café robusta. Segundo o autor, o percentual de caveol em relação ao de cafestol variou de 1,0\% (Filipinas) até 7\% (Uganda), mas em nenhum caso foi observada ausência 
do composto. Usando cromatografia a gás com espectrômetro de massa (GC-EM), cromatografia em fase líquida de alta precisão (HPLC) e ressonância nuclear magnética (RMN), constatou que o perfil de álcoois e monoésteres é bastante similar nos dois tipos de café. Porém, a quantidade total de ésteres mostrou-se cerca de $50 \%$ menor no robusta. Apenas um tipo de éster do cafestol foi identificado, o palmitato, enquanto para o caveol foram identificados o linoleato, o palmitato, o oleato, o estearato e o eicosanoato. Na porção não-esterificada ocorre 10 vezes mais cafestol do que caveol.

FIGURA1 - ESTRUTURADE ÁLCOOIS DITERPÊNICOS DO ÓLEO DE CAFÉ: A-CAFESTOL; B-CAVEOL; C-16-O-METILCAFESTOL

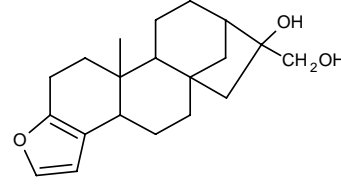

A

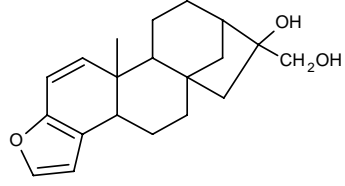

B

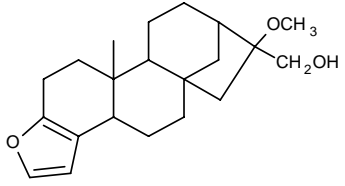

C

Alguns autores atribuem a SPEER \& MISCHNICK (38) a identificação do 16-O-metilcafestol, mas em PETTITT JR. (31) verifica-se a primeira menção ao composto. A estrutura proposta como metoxi-cafestol, nada mais é do que a do 16-O-metilcafestol, (Figura 1), encontrado apenas em cafés robusta e excelsa (Coffea dewevrei De Wild e Durand). SPEER et al. (39) obtiveram em 10 amostras de café robusta o total de 0,67 a 1,54 g de 16O-metilcafestol $/ \mathrm{kg}$ de amostra (base úmida), sendo $1,7 \%$ na forma livre. O diterpeno é um componente menor e não sofre modificações com a torrefação. Já o cafestol e o caveol podem sofrer desidratação formando dehidroderivados (27).

LERCKER et al. (25) avaliaram a composição dos álcoois diterpênicos por CGAR, após silanização do material insaponificável. Encontraram nas amostras de café arábica, teor destes álcoois de 851,3-1290,7 (mg/ $100 \mathrm{~g}$ ) de lipídios e nas de café robusta 158,8-361,4 mg/100 g de lipídios, portanto, diferença bastante acentuada entre as espécies (Tabela 7). 


\section{TABELA 7 - ÁLCOOIS DITERPÊNICOS DO INSAPONIFICÁVEL TOTAL DE AMOSTRAS DE CAFÉ, EM mg/100 g DE LIPÍDIOS}

\begin{tabular}{lllll}
\hline \multicolumn{1}{c}{ Componente } & \multicolumn{2}{c}{ Café arábica } & \multicolumn{2}{c}{ Café robusta } \\
& Verde & Torrado & Verde & Torrado \\
\hline Dehidrocafestol & $\operatorname{tr}$ & $30,0-79,2$ & & tr-0,5 \\
Dehidrocaveol & $2,6-3,4$ & $46,9-83,3$ & & $14,8-32,4$ \\
Caveol & $431,2-663,6$ & $371,1-672,7$ & 14,2 & $3,6-12,5$ \\
Cafestol & $414,2-533,7$ & $299,4-583,6$ & 113,0 & $76,4-190,1$ \\
N.I. & $0,8-1,7$ & $0,9-3,2$ & & $\operatorname{tr}-0,4$ \\
16-O-metilcafestol & $2,4-3,0$ & $1,8-14,5$ & 70,7 & $45,3-138,9$ \\
\hline
\end{tabular}

Fonte: LERCKER et al. (27); $\operatorname{tr}$ = traços (valores não-quantificados nas condições de análise).

N.I. = Não-identificado.

\section{ESTERÓIS}

Os esteróis representam, em geral, os componentes majoritários do material insaponificável na maioria dos óleos vegetais. Em óleo de café, no entanto, os principais componentes são os álcoois diterpênicos, cafestol e caveol, seja na forma livre ou como monoésteres de ácidos graxos.

Os esteróis, sempre acompanhados de 4-metilesteróis e 4,4dimetilesteróis (álcoois triterpênicos), apresentam menor concentração no material insaponificável.

ITOH et al. (19) analisaram óleo de café brasileiro contendo 3,4\% de matéria insaponificável, fracionando-a por cromatografia em camada delgada, desprezando os componentes mais polares que os esteróis, ou seja, os álcoois diterpênicos. A cromatografia gás-líquido destas frações foi realizada empregando-se coluna de vidro, $2 \mathrm{~m} \times 3 \mathrm{~mm}$ d.i., com fase sólida GasChrom Z, 80-100 mesh e coberta com fase líquida de 1,5\% de OV-17. TISCORNIA et al. (41) utilizaram colunas empacotadas (SE-30 e OV-17) para analisar os esteróis extraídos após saponificação do óleo, fracionamento por cromatografia em camada delgada (CCD) e silanização da banda extraída. FREGA et al. (10), pelo que se sabe, foram os primeiros a usar coluna polar de alta resolução (TAP, Chrompack) para melhor separação entre esteróis, 4-metilesteróis e 4,4-dimetilesteróis de óleo de café. A matéria insaponificável foi extraída, metilada com diazometano e 
silanizada, previamente à análise. Os resultados obtidos por estes três grupos de autores são similares, apesar das diferentes técnicas empregadas (Tabela 8).

\section{TABELA 8 - COMPOSIÇÃO RELATIVA (\%) DA FRAÇÃO ESTERÓLICA DE ÓLEOS DE CAFÉ}

\begin{tabular}{lccc}
\hline Componente & 1 & 2 & 3 \\
\hline Colesterol & 0,8 & $\operatorname{tr}-0,5$ & $\operatorname{tr}$ \\
N.I. & 2,4 & & \\
Campesterol & 14,2 & $14,8-18,7$ & 19 \\
N.I. & 2,4 & & \\
Estigmasterol & 24,6 & $19,6-24,5$ & 20 \\
Sitosterol & 42,5 & $42,7-56,5$ & 54 \\
$\Delta^{5}$-avenasterol & 13,1 & $2,0-14,6$ & 6 \\
$\Delta^{7}$-estigmastenol & & $0,6-6,6$ & 1 \\
$\Delta^{7}$-avenasterol & $\operatorname{tr}$ & $\operatorname{tr}-4,4$ & $\operatorname{tr}$ \\
\hline
\end{tabular}

1 FREGA et al. (10): outros 4 componentes-traço não foram identificados. 2 TISCORNIA et al. (41): entre 20 amostras de C. arábica, cinco brasileiras.

3 ITOH et al. (19); tr = traços (valores não-quantificados nas condições de análise). N.I. = Não-identificado.

FREGA et al. (11) analisaram, simultaneamente, por cromatografia a gás, os esteróis e os álcoois triterpênicos de 10 amostras de café arábica e sete de robusta, de diversas procedências. Encontraram diferenças marcantes no teor de sitosterol (superior no arábica) e no de $\Delta^{5}$-avenasterol (superior no robusta), conforme a Tabela 9.

O total dos componentes, em mg/100 g de lipídios, foi de 87,1-165,9 para o arábica e de 89,8-175,9 para o robusta.

O percentual relativo encontrado por ITOH et al. (20) foi de $37 \%$ de cicloartenol e 54\% de 24-metilenocicloartanol, ambos dimetilesteróis. Como principais monometilesteróis, os mesmos autores encontraram o obtusifoliol (26\%), o gramisterol (43\%) e o citrostadienol (26\%), composição semelhante à de outros óleos vegetais. Além destes autores, NAGASAMPAGl et al. (30) identificaram os componentes dos grãos de café (Tabela 10), empregando CG-EM, coluna empacotada SE-30. 


\section{TABELA9- COMPOSIÇÃO DE ESTERÓIS E ÁLCOOIS TRITERPÊNICOS, EM LIPÍDIOS DE GRÃOS DE CAFÉ ARÁBICA E ROBUSTA}

\begin{tabular}{lcc}
\hline Componente & Café arábica & Café robusta \\
\hline Cicloartenol & $4,7-7,1$ & $4,8-6,4$ \\
24-metilenocicloartanol & $7,4-10,1$ & $6,0-9,2$ \\
N.I. & $0,8-1,9$ & $1,4-2,6$ \\
Colesterol & tr-2,0 & $0,3-1,3$ \\
N.I. & $2,0-4,4$ & $2,4-3,6$ \\
Campesterol & $9,0-14,0$ & $9,6-13,6$ \\
N.I. & $0,1-0,4$ & $1,7-2,3$ \\
Estigmasterol & $16,9-19,4$ & $16,2-20,9$ \\
Sitosterol & $39,1-45,3$ & $33,1-37,2$ \\
$\Delta^{5}$-avenasterol & $2,0-4,2$ & $9,6-15,5$ \\
Sitostanol & $1,4-3,6$ & $0,2-0,4$ \\
\hline
\end{tabular}

Fonte: FREGA et al. (11); $\operatorname{tr}=$ traços (valores não-quantificados nas condições de análise).

N.I. = Não-identificado.

TABELA 10 - DISTRIBUIÇÃO DOS ESTERÓIS* EM GRÃOS DE CAFÉ (30)

\begin{tabular}{lccc}
\hline \multirow{2}{*}{ Esterol } & \multicolumn{3}{c}{ \% relativa nos grãos } \\
\cline { 2 - 4 } & Esterificados & Livres & Total $^{\star *}$ \\
\hline Cicloartenol & 1,3 & 0,2 & 1,5 \\
24-metilenocicloartanol & 3,0 & 0,7 & 3,7 \\
Cicloeucalenol & 0,4 & 0,1 & 0,5 \\
Obtusifoliol & 0,4 & 0,1 & 0,5 \\
24-metilenolofenol & 0,3 & 0,1 & 0,4 \\
Citrostadienol & 0,5 & 0,1 & 0,6 \\
Campesterol & 11,3 & 6,5 & 17,8 \\
Sitosterol & 33,5 & 19,3 & 52,8 \\
Estigmasterol & 9,3 & 12,8 & 22,1 \\
Total & 60,0 & 39,9 & 99,9 \\
\hline
\end{tabular}

* O teor de esteróis nos lipídios é de 5,4\% e, neste caso, engloba dimetilesteróis, monometilesteróis e desmetilesteróis.

** Também presentes $0,4 \%$ de estigmastanol e $0,1 \%$ de campestanol. 


\section{ANTIOXIDANTES}

Encontram-se poucas referências sobre a presença de antioxidantes no óleo de café cru. FOLSTAR et al. (8), por exemplo, encontraram teor de tocoferóis totais de 400-600 ppm.

Entre várias matérias-primas, WURZIGER \& HARMS (45) encontraram o maior teor de 5-hidroxitriptamidas de ácidos graxos em grãos de café, ou seja, 375-1440 ppm. Também observaram, no mesmo trabalho, pronunciada atividade antioxidante dos compostos.

Aparentemente, as hidroxitriptamidas estão nas ceras do grão (10) e, portanto, se os grãos não forem previamente decerados, serão extraídas junto com o óleo, dada a semelhança de polaridade.

\section{DIFERENCIAÇÃO ENTRE CAFÉ ARÁBICA E ROBUSTA PELA FRAÇÃO LIPÍDICA}

A partir da matéria insaponificável, de fracionamento por cromatografia em camada fina e medidas espectrofotométricas, SZPIZ et al. (40) quantificaram cafestol e caveol em seis amostras de óleo de café arábica e cinco de robusta. Usaram os valores da absortividade dos componentes em metanol, a 224 e $289 \mathrm{~nm}$ [log $\in=3,78$ e 4,03, respectivamente, segundo KAUFMANN \& SEN GUPTA (22)]. Apesar das dificuldades experimentais, o teor de caveol do café robusta mostrou-se inferior ao arábica e, em nenhum caso, chegou a 1\% (Tabela 11).

\section{TABELA 11 - TEOR DE CAFESTOL E CAVEOL EM ÓLEOS DE CAFÉ}

\begin{tabular}{lcc}
\hline Óleo de café & Teor de cafestol & Teor de caveol \\
\hline Arábica & & \\
1 & 8,76 & 1,31 \\
2 & 7,45 & 1,33 \\
3 & 5,65 & 4,91 \\
4 & 5,96 & 5,21 \\
5 & 7,02 & 1,38 \\
6 & 8,27 & 1,67 \\
Robusta & & \\
1 & 6,85 & 0,45 \\
2 & 11,59 & 0,48 \\
3 & 6,10 & 0,05 \\
4 & 13,16 & 0,44 \\
5 & 6,96 & 0,61 \\
\hline
\end{tabular}

Fonte: SZPIZ et al. (40). 
CLIFFORD, apud SMITH (37), usou dados químicos para diferenciar as duas espécies com sucesso parcial, já que muitos componentes do café não foram identificados.

SPEER et al. (39) analisaram por cromatografia em fase líquida de alta eficiência, os álcoois diterpênicos, escolhendo como elemento indicador da presença de café robusta o 16-O-metilcafestol.

Para evitar métodos químicos, morosos, KEMSLEY et al. (23) tentaram discriminar Coffea arábica de C. robusta usando espectrômetro de infravermelho, com transformada de Fourier e equipado com acessório de reflectância difusa. Os dados foram submetidos não só à análise discriminante clássica como também à análise de componentes principais (PCA). Embora os autores tenham realizado o estudo com grãos de café, o método foi citado porque a absortividade dos lipídios desempenhou papel importante na análise espectral, devido à banda característica da carbonila (ca. $1744 \mathrm{~cm}^{-1}$ ). O método, todavia, não foi validado, pois amostras certificadas não estavam disponíveis.

MARIANI \& FEDELI (28) estudaram 30 amostras (sendo quatro de origem brasileira), além de misturas entre elas. Sem exceção, os componentes presentes nas duas espécies foram os mesmos, como pode ser visto na Tabela 12. Existem pequenas diferenças de ordem quantitativa, como a do 24-metilenocolesterol (componente então relatado pela primeira vez), que no robusta variou de 1,5 a 2,4\% do total de esteróis e no arábica de 0 a $0,4 \%$. O teor de $\Delta^{5}$-avenasterol foi mais elevado no robusta $(5,1$ $12,6 \%)$ do que no arábica (1,6-4,1\%). Foram também encontradas pequenas diferenças nos teores de sitostanol. A composição de esteróis serve para diferenciar óleos em alguns casos e para detectar fraudes em óleos de oliva. Mas no caso de diferenciação de espécies de café, os autores não consideraram a determinação da composição de esteróis como método analítico decisivo para avaliar as misturas, apenas como elemento relativo de avaliação, com grande margem de erro. Esta opinião não é compartilhada por CARRERA et al. (5), que analisaram a fração esterólica de 19 amostras de café arábica e 12 de robusta, tendo encontrado valores semelhantes aos de MARIANI \& FEDELI (28). Estes acreditam que os componentes com maior potencial para diferenciação entre os óleos sejam o sitostanol e o $\Delta^{5}$-avenasterol, afirmando que, com base no seu teor e empregando análise de componente principal (PCA) e de "clusters", qualquer amostra pura pode ser facilmente classificada. 


\section{TABELA 12 - COMPOSIÇÃO RELATIVA (\%) DA FRAÇÃO ESTERÓLICA DE CAFÉS ARÁBICA E ROBUSTA}

\begin{tabular}{lcccc}
\hline \multirow{2}{*}{ Componente } & Valores máximo e mínimo & \multicolumn{2}{c}{ Valores médios } \\
\cline { 2 - 5 } Colesterol & Arábica & Robusta & Arábica & Robusta \\
24-metilenocolesterol & $0,2-0,4$ & $0,1-0,3$ & 0,3 & 0,2 \\
Campesterol & $0,0-0,4$ & $1,5-2,4$ & 0,2 & 1,9 \\
Campestanol & $4,7-17,0$ & $15,5-18,8$ & 15,8 & 16,9 \\
Estigmasterol & $0,2-0,6$ & $0,1-0,3$ & 0,4 & 0,2 \\
$\Delta^{7}$-campesterol & $20,5-23,8$ & $20,0-26,7$ & 21,9 & 23,1 \\
$\Delta^{5}$-estigmastadienol & $0,4-1,2$ & $0,1-0,6$ & 0,6 & 0,2 \\
Clerosterol & $0,2-0,5$ & $0,1-2,0$ & 0,3 & 0,5 \\
Sitosterol & $0,2-0,8$ & $0,5-1,0$ & 0,5 & 0,7 \\
Sitostanol & $6,7-53,8$ & $40,6-50,7$ & 51,6 & 0,8 \\
$\Delta^{5}$-avenasterol & $1,4-2,8$ & $0,5-1,2$ & 2,0 & 9,1 \\
$\Delta^{5,24}$-estigmastadienol & $1,6-4,1$ & $5,1-12,6$ & 2,7 & 0,0 \\
$\Delta^{7}$-estigmastenol & $0,0-0,4$ & $0,0-0,3$ & 0,1 & 0,2 \\
$\Delta^{7}$-avenasterol & $0,0-4,5$ & $0,1-0,8$ & 2,2 & 0,4 \\
\hline
\end{tabular}

FONTE: MARIANI \& FEDELI (28).

\section{COMPORTAMENTO FÍSICO}

HARTMAN et al. (14) e HARTMAN \& LAGO (13) procuraram demonstrar que o comportamento físico do óleo de café está intimamente ligado aos ésteres de cafestol e caveol, sendo, portanto, menos dependente da composição em ácidos graxos e/ou triacilglicerólica. O ponto de fusão do óleo de café é baixo $\left(7,8^{\circ} \mathrm{C}\right)$ e não reflete a composição em ácidos graxos e triacilglicerólica. Além disso, a perda no refino de óleos de café é muito superior ao que seria esperado em função do teor de ácidos graxos livres. Todavia, o efeito emulsificante do material insaponificável e, particularmente, dos monoésteres de cafestol e caveol não foi conclusivamente demonstrado pelos autores.

\section{IMPLICAÇÕES FISIOLÓGICAS DOS LIPÍDIOS DO CAFÉ}

Diversos estudos, ainda sujeitos a muitas controvérsias, têm sido publicados sobre eventuais efeitos dos lipídios do café nas taxas de colesterol.

RATNAYAKE et al. (32) examinaram os lipídios em vários tipos e preparações de café, incluindo várias marcas comerciais de café solúvel. O teor variou conforme o método de preparação, mas a composição não. A bebida filtrada continha menos de $7 \mathrm{mg}$ de lipídios $/ 150 \mathrm{~mL}$, mas aquela 
preparada por fervura, não-filtrada, e o café expresso atingiam níveis de 60-160 mg/150 mL. A bebida filtrada com retentor metálico continha $50 \mathrm{mg}$ de lipídios/150 mL. Durante a filtração com papel, os lipídios ficam retidos na borra e a bebida e o filtro retêm apenas 0,4 e 9,4\%, respectivamente, do total de lipídios recuperados. Triacilgliceróis e ésteres de álcoois diterpênicos foram as principais classes de lipídios observadas nas bebidas de café. Lipídios em bebidas feitas com café solúvel, tanto normal quanto descafeinado, variaram ligeiramente de uma marca para a outra, na faixa de 1,8 a 6,6 mg/150 mL.

WEUSTEN-VAN DER WOUW et al. (43) em extenso estudo clínico, usando frações purificadas de cafestol e caveol, misturas de ésteres dos diterpenos, triacilgliceróis purificados do óleo de café e outros afirmaram que o cafestol e, possivelmente, o caveol são responsáveis pela elevação de taxa de colesterol no organismo humano. O mecanismo desta ação é desconhecido, porém acompanhado por alterações na função enzimática do fígado. Todavia, a forma que a bebida de café é ingerida é fundamental para que haja esse efeito, uma vez que se filtrada, o cafestol e o caveol ficam retidos na borra de filtração. Sendo assim, tais conseqüências ficam restritas aos países cujos habitantes têm por hábito ingerir o que se conhece como café fervido, como na Escandinávia. Foi observado na Finlândia, num período de 25 anos, $40 \%$ de redução da taxa de colesterol, fato atribuído à mudança no hábito de ingerir café filtrado ao invés de café fervido. A mudança provocou redução de $7 \%$ em doenças cardiovasculares. Os autores constataram que para cada $10 \mathrm{mg}$ de cafestol ingeridos por dia ocorre acréscimo do colesterol no soro em $5 \mathrm{mg} / \mathrm{dL}$ ou $0,13 \mathrm{mmol} / \mathrm{L}$.

Usando ratos, aos quais foram administradas diversas dietas contendo diferentes lipídios, HUGGET et al. (16) observaram aumento significativo de colesterol no plasma dos animais alimentados com a dieta contendo $2,5 \%$ de óleo de café.

RATNAYAKE et al. (33) afirmaram que os lipídios do café apresentam ação hipercolesterolêmica em cobaias. Sugeriram que os diterpenos poderiam ser as substâncias responsáveis por tal efeito, notado quando a dieta é pobre em ácidos saturados. No caso de dietas ricas em ácidos saturados este efeito pode ser mascarado.

URGERT et al. (42) mediram de 1-10 mg de cafestol/150 mL em bebida de café preparada à moda escandinava e turca/grega. Afirmaram que os diterpenos, cafestol e caveol, presentes em café não-filtrado e em finos sobrenadantes (café turco, por exemplo) elevam o colesterol. Tal afirmativa 
foi posteriormente criticada por GURR (12), com base em flutuações sazonais no teor de colesterol no sangue e no fato dos autores terem usado doses anormalmente altas de café forte.

AL-KANHAL et al. (1) ao alimentarem ratas com óleo de café e matéria insaponificável verificaram que o cafestol e o caveol não são os únicos fatores que causam elevação do colesterol.

A elevação da concentração de homocisteína ${ }^{1}$ no plasma tem sido sugerida como suposto fator de risco para doença cardiovascular. Estudo recente sobre os efeitos de beber 1 litro/dia de café não-filtrado, acusou aumento significativo de $10 \%$ no nível de homocisteína no plasma (18). A base para a afirmação é desconhecida. Está ainda para ser estabelecida qualquer influência dos diterpenos presentes no café não-filtrado.

Esteróis oxidados, produtos de processamento, podem ser encontrados no café, mas a preocupação é com o oxicolesterol, reputado como o "colesterol ativo". Como o colesterol ocorre, em óleos de café, apenas em quantidades traço, LERCKER et al. (27) mediram na verdade o 7cetositosterol, encontrando valores inferiores a $0,04 \mathrm{mg} / \mathrm{kg}$ de lipídios, tanto em café cru quanto torrado.

Experiências com ratos, efetuadas por HASEGAWA et al. (15), evidenciaram que o café e compostos relacionados não apresentam ação carcinogênica para o fígado dos animais testados.

\section{USOS}

De acordo com ROMPONI (36) o óleo de café verde apresenta propriedades hidratantes, emolientes e amaciantes superiores às dos óleos comuns, enquanto o óleo do grão torrado é usado para aromatização de cafés solúveis e produtos de confeitaria. A cor escura e o odor intenso do óleo de grãos torrados impossibilitam sua utilização na indústria de cosméticos.

O óleo de café é utilizado, ainda, em cafés instantâneos, cafés líquidos em lata, "iced coffee", "cappuccinos", sobremesas, sorvetes, pudins, doces e outros preparados à base de leite (4).

${ }^{1}$ Homocisteína é o ácido 2-amino-4-mercaptobutírico, subproduto normal do metabolismo da metionina. 
Segundo WURZIGER (44) a espécie robusta não apresenta caveol, o que pode estar ligado ao sabor mais apurado da espécie arábica como mencionam BRIANDET et al. (2).

A utilização do óleo de café, como óleo comestível, parece estar ligada à redução ou eliminação do material insaponificável, no qual predominam os álcoois diterpênicos e seus ésteres.

\section{CONCLUSÃO}

As principais espécies de café produzidas são a arábica e a robusta, comercializadas como tal ou na forma de "blends".

Os dados encontrados na literatura sobre o teor e a composição dos lipídios de grãos de café verde e torrado variam bastante conforme a espécie estudada e entre os autores.

Os lipídios do café constituem classes diferenciadas e específicas destacando-se a presença de álcoois diterpênicos, sobretudo o cafestol e o caveol, que ocorrem na forma livre ou na forma de monoésteres de ácidos graxos, cuja composição também é diferenciada.

A distinção entre cafés torrados e seus óleos pode ser efetuada de várias maneiras, uma delas mediante as diferenças na composição dos esteróis ou dos álcoois diterpênicos.

Aos álcoois diterpênicos, prováveis responsáveis pela dificuldade na refinação do óleo, também é atribuída a elevação de taxas de colesterol para os que ingerem, diariamente, muitas xícaras da bebida não-filtrada.

\section{Abstract}

\section{LIPIDS IN COFFEE GRAINS}

In this paper several aspects related to the content, the use and the composition of the lipids present in arabica and robusta coffee grains, green or toasted, and in some of its derivates are reviewed. The main differences between the species are discussed as well as the possible health implications due to cafestol and kahweol, the main products of the unsaponifiable material. Lipid content in green and toasted coffee seeds is different. Lipid composition varies among species and authors. Considered as a sole parameter, fatty acid composition, in which predominate linolenic and palmitic acids, would be responsible for a higher coffee oil melting point. The main differences between species 
are the unsaponifiable content and composition, especially concerned to diterpenic alcohols, cafestol and kahweol and their esters. To these compounds, has been attributed hypercolesterolemic effect due to the ingestion of not filtered coffee drink.

KEY-WORDS: COFFEA; CAFESTOL; KAHWEOL; COFFEE SPENT GROUND.

\section{REFERÊNCIAS}

1 AL-KANHAL, M. A.; AHMED, F.; ARIF, Z. Effect of coffee and its unsaponifiable fraction on plasma cholesterol level in female rats. Intern. J. Food Science \& Nutrition, New York, v.50, n.2, p.99103, 1999.

2 BRIANDET, R.; KEMSLEY, E.K.; WILSON, R.H. Discrimination of arabica and robusta in instant coffee by Fourier transform infrared spectroscopy and chemometrics. J. Agric. Food Chem., Columbus, v. 44, n.1, p.170-174, 1996.

3 CALZOLARI, C.; CERMA, E. Coffee fatty substances. Riv. Ital. Sost. Grasse, Milão, v.40, n.4, p.176-80, 1963.

4 CIA IGUAÇÚ DE CAFÉ SOLÚVEL. Disponível em: <http:// www.iguacu.com.br/prod/ptoleo.htm>. Acesso em set. 2000.

5 CARRERA, F.; LEÓN-CAMACHO, M.; PABLOS, F.; GONZALEZ, A.G. Authentication of green coffee varieties according to their sterolic profile. Analytica Chimica Acta, New York, v.370, n.2/3, p.131139, 1998.

6 CLIFFORD, M.N. Physical properties of the coffee bean. Tea Coffee and Trade J., New York, v.158, n.5, p.30-33, 1986.

7 DJERASSI, C.; CAIS, M.; MITSCHER, L.A. Terpenoids XXXVII. The structure of the pentacyclic diterpene cafestol. on the absolute configuration of diterpenes and alkaloids of the phyllocladene group. J. Am. Chem. Soc., Washington, v.81, n.5, p.2386-2398, 1959.

8 FOLSTAR, P.; VAN DER PLAS, H.C.; PILNIK, W.; DE HEUS, J.G. Tocopherols in the unsaponifiable matter of coffee bean oil. J. Agric. Food Chem., Columbus, v.25, n.2, p.283-285, 1977.

9 FOlStAR, P. Lipids. In: CLARKE, R.J.; MACRAE, R. Coffee. 
London: Elsevier App. Sci., 1985. v. 1, p. 203-222.

10 FREGA, N.; BOCCI, F.; GIOVANNONI, G.; LERCKER, G. High resolution $\mathrm{GC}$ of unsaponifiable matter and sterol fraction in vegetable oils. Chromatographia, Braunschweig, v.36, n.4, p.215-217, 1993.

11 FREGA, N.; BOCCI, F.; LERCKER, G. High resolution gas chromatographic method for determination of robusta coffee in commercial blends. J. High Res. Chromatography, New York, v.17, n.5, p.303-307, 1994.

12 GURR, M. I. Coffee drinking, plasma cholesterol and coronary heart disease risk: a commentary. British J. Cardiology, Londres, v.4, n.1, p.51-53, 1997.

13 HARTMAN, L.; LAGO, R.C.A. Further observations concerning effects of unsaponifiable constituents on the properties of coffee seed oil. J. Am. Oil Chem. Soc., Champaign, v. 50, n.2, p.99-100, 1973.

14 HARTMAN, L.; LAGO, R.C.A.; TANGO, J.S.; TEIXEIRA, C.G. The effect of unsaponifiable matter on the properties of coffee seed oil. $\mathbf{J}$. Am. Oil Chem. Soc., Champaign, v. 45, n.8, p.577-9, 1968.

15 HASEGAWA, R.; OGISO, T.; IMAIDA, K.; SHIRAI, T.; ITO, N. Analysis of the potential carcinogenicity of coffee and its related compounds in a medium-term liver bioassay on rats. Food Chem. Toxicol., New York, v.33, n.1, p.15-20, 1995.

16 HUGGET, A.C.; MARCHESINI, M.; PERRIN, I. Effects of coffee oil on plasma cholesterol in rat. In: SCIENTIFIC SYMPOSIUM ON COFFEE, 15., 1993. Proceedings... Lausanne: ASIC, 1993. p. 497-503.

17 IARC. International Agency for Research on Cancer. Monographs on the evaluation of carcinogenic risks to humans: coffee, tea, mate, methylxanthines and methylglyoxal. Lyon, France: 1991. v. 51.

18 COFFEE and CVD. Inform, Champaign, v. 11, n.4, p.415, 2000.

19 ITOH, T.; TAMURA.T.; MATSUMOTO, T. Sterol composition of 19 vegetable oils. J. Am. Oil Chem. Soc., Champaign, v. 50, n.4, p.122-5, 1973a. 
20 ITOH, T.; TAMURA.T.; MATSUMOTO, T. Methylsterol composition of 19 vegetable oils. J. Am. Oil Chem.Soc, Champaign, v. 50, n.8, p.300-3, 1973b.

21 KAUFMANN, H. P.; HAMSAGAR, R. S. The lipids of the coffee seeds. I. The fatty acid esters of cafestol. Fette Seifen Anstrichmittel, Berlim, v.64, n.3, p.206-213, 1962.

22 KAUFMANN, H. P.; SEN GUPTA, A. K. The information about the lipids of coffeebeans. III. The preparation of pure kahweol. Fette Seifen Anstrichmittel, Berlim, v.65, n.7, p.529-532, 1963.

23 KEMSLEY, E. K.; RUAULT, S.; WILSON, R. H. Discrimination between Coffea arabica and C. canephora variant robusta beans using infrared spectroscopy. Food Chem., Amsterdam, v.54, n.3, p.321-326, 1995.

24 KHAN, N. A.; BROWN. J. B. The composition of coffee oils and its component fatty acids. J. Am. Oil. Chem. Soc., Champaign, v. 30, n.12, p.606-609, 1953.

25 LERCKER, G.; FREGA,; N., BOCCI, F.; RODRIGUEZ-ESTRADA, $M$. T. High resolution gas chromatographic determination of diterpenic alcohols and sterols in coffee lipids. Chromatographia, Braunschweig, v. 41, n.112, p.29-33, 1995.

26 LERCKER, G.; CABONI, M. F.; BERTACCO, G.; TURCHETTO, E.; LUCCI, A.; BORTOLOMEAZZI, R.; PAGANI, E.; FREGA, N.; BOCCI, F. La frazione lipidica del caffè. Nota 1: Influenza della torrefazione e della decaffeinizzazione. Industrie Alimentari, Pinerolo, v.35, n.10, p. 1057-1065, 1996a.

27 LERCKER, G.; CABONI, M. F.; BERTACCO, G.; TURCHETTO, E.; LUCCI, A.; BORTOLOMEAZZI, R.; PAGANI, E.; FREGA, N.; BOCCI, $\mathrm{F}$. La frazione lipidica del caffè. 2: Su alcuni parametri di qualificazione. Industrie Alimentari, Pinerolo, v.35, n.11, p. 1186-1193, 1996b.

28 MARIANI, C.; FEDELI, E. Gli steroli delle specie arabica e robusta dell caffè. Riv. Ital.Sost. Grasse, Milão, v. 68, n.3, p.111-115, 1991.

29 NACKUNSTZ, B.; MAIER, H.G. Diterpenoide im kaffee. III. Cafestol und kahweol. Z. Lebensm. Unters Forsch, Berlim, v. 184, n.6, p.494-499, 1987. 
30 NAGASAMPAGI, B. A.; ROWE, J. W.; SIMPSON, R.; GOAD, L. J. Sterols of coffee. Phytochemistry, Oxford, v.10, n.6, p.1101-1107, 1971.

31 PETTITT JR., B. C. Identification of the diterpene esters in arabica and canephora coffees. J. Agric. Food Chem., Columbus, v.35, n.4, p.549-551, 1987.

32 RATNAYAKE, W.M.N.; HOLLYWOOD, R.; O'GRADY, E.; STAVRIC, B. Lipid content and composition of coffee brews prepared by different methods. Food and Chem. Toxicol., New York, v.31, n.4, p.263269, 1993.

33 RATNAYAKE, W.M.N.; PELLETIER, G.; HOLLYWOOD, R.; MALCOM, S.; STAVRIC, B. Investigation of the effect of coffee lipids in serum cholesterol in harmsters. Food \& Chem. Toxic., New York, v.33, n.3, p.195-201, 1995.

34 RAVINDRANATH, R.; YOUSUF ALI KHAN, R.; OBI REDDY, T. Composition and characteristics of indian coffee bean, spent grounds and oil. J. Sci. Food. Agric., Londres, v. 23, n.3, p.307-310, 1972.

35 REWALD, B. The phosphatides and oil in unroasted and roasted coffee beans. Oil \& Soap, Chicago, v. 23, n.1, p.19-20, 1946.

36 ROMPONI, M. Indústria usa óleo de café verde para a fabricação de cosméticos. Jornal Folha de São Paulo, 28 de jul. 1998. p.3 (Suplemento Agrofolha 5).

37 SMITH, A.W. Introduction. In: CLARKE, R.J.; MACRAE, E.R. (Eds.). Coffee: chemistry. London: Elsevier Appl. Sci., 1985. v.1, p. 1-41.

38 SPEER, K.; MISCHNICK, P. 16-O-methylcafestol: a new diterpene in coffee. Discovery and identification. Z. Lebensm. Unters. Forsch., Berlim, v.189, n.3, p.219-222, 1989.

39 SPEER, K.; TEWIS, R.; MONTAG, A. 16-O-methylcafestol- a new diterpene in coffee. Free and bound 16-O-methylcafestol. Z. Lebensm. Unters. Forsch., Berlim, v. 192, n. 5, p. 451-454, 1991.

40 SZPIZ, R. R.; JABLONKA, F.H.; PEREIRA, D.A. Composição em ácidos graxos: triacilgliceróis, monoésteres de diterpenos e óleo de 
grãos de café. In: CONGRESSO BRASILEIRO DE CIÊNCIA E TECNOLOGIA DE ALIMENTOS, 1989, Rio de Janeiro. Resumos... Rio de Janeiro: SBCTA, 1989. p. 151.

41 TISCORNIA, E.; CENTI-GROSSI, M.; TASSI-MICCO, C.; EVANGELISTI, F. La frazione sterolica dell'olio di caffè (Coffea arabica L.). Riv. Ital. Sost. Grasse, Milão, v.61, n.8, p.283-292, 1979.

42 URGERT, R.; VAN DER WEG, G.; KOSMEIJER-SCHUIL, T. G.; VAN DEN BOVENKAMP, P.; HOVENIER, R.; KATAN, M.B. Levels of the cholesterol-elevating diterpenes cafestol and kahweol in various coffee brews. J. Agric. Food Chem., Columbus, v.43, n.8, p.2167-2172, 1995.

43 WEUSTEN-VAN DER WOUW, M.P.M.E.; KATAN, M.B.; VIANI, R.; HUGGETT, A.C.; LIARDON, R.; LUND-LARSEN, P.G.; THELLE, D.S.; AHOLA, I.; ARO, A.; MEYBOOM, S.; BEYNEN, A.C. Identity of the cholesterol-raising factor from boiled coffee and its effects on liver function enzymes. J. Lipid Res., Bethesda, v.35, n.4, p.721-733, 1994.

44 WURZIGER, J. Contribuição para a composição do óleo de grãos crus de café arábica e robusta. Kaffee und Tee Markt, Berlim, v.26, n.12, p.3-7, 1976.

45 WURZIGER, J.; HARMS, U. Tryptamides of carboxylic acids in oilcontaining seeds. Fette Seifen Anstrichmittel, v. 75, n.2, p.121126, 1973. 